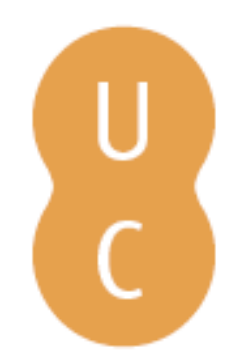

\title{
nommalina
}

\section{Ammaia: transformação e mudança na paisagem urbana}

\author{
Autor(es): $\quad$ Pereira, Sérgio
}

Publicado por: Associação Portuguesa de Estudos Clássicos; Centro de Estudos

URL

persistente: URI:http://hdl.handle.net/10316.2/31551

DOI: $\quad$ DOI:http://dx.doi.org/10.14195/978-989-8281-69-2_12

Accessed : $\quad$ 26-Apr-2023 15:20:41

A navegação consulta e descarregamento dos títulos inseridos nas Bibliotecas Digitais UC Digitalis, UC Pombalina e UC Impactum, pressupõem a aceitação plena e sem reservas dos Termos e Condições de Uso destas Bibliotecas Digitais, disponíveis em https://digitalis.uc.pt/pt-pt/termos.

Conforme exposto nos referidos Termos e Condições de Uso, o descarregamento de títulos de acesso restrito requer uma licença válida de autorização devendo o utilizador aceder ao(s) documento(s) a partir de um endereço de IP da instituição detentora da supramencionada licença.

Ao utilizador é apenas permitido o descarregamento para uso pessoal, pelo que o emprego do(s) título(s) descarregado(s) para outro fim, designadamente comercial, carece de autorização do respetivo autor ou editor da obra.

Na medida em que todas as obras da UC Digitalis se encontram protegidas pelo Código do Direito de Autor e Direitos Conexos e demais legislação aplicável, toda a cópia, parcial ou total, deste documento, nos casos em que é legalmente admitida, deverá conter ou fazer-se acompanhar por este aviso.

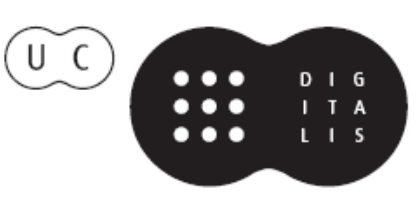




\section{Espaços e Paisagens}

Antiguidade Clássica

e Heranças Contemporâneas

Vol. III

Francisco Oliveira, Jorge Oliveira e Manuel Patrício

IMPRENSA DA UNIVERSIDADE DE COIMBRA 


\title{
AMMAIA: TRANSFORMAÇÃO E MUDANÇA \\ NA PAISAGEM URBANA
}

\author{
SÉrgio PEREIRA \\ Arqueólogo / CIDEHUS
}

\section{Résumé}

La ville romaine de Ammaia marquerait de façon définitive le paysage de la région portugaise que nous connaissons aujourd'hui en tant que Alentejo Nord. Les fouilles arquéologiques commencées en 1995 nous ont permis de découvrir quelques morceaux du paysage urbain. Dès sa fondation jusqu'à son abandon, la ville s'est transformée et adaptée aux nouvelles éxigences publiques et privées. Aujourd'hui, nous pouvons contempler un enchevêtrement de structures, certaines presque effacées, d'autres conservées, d'autres encore superposées, nous difficultant la compréhension. L'analyse des structures et des respectifs contextes arquéologiques nous ont permis d'isoler certaines constructions ou édifices, nous faisant mieux comprendre la transformation et le changement du paysage urbain de Ammaia.

Keywords: Ammaia, Marvão, paysage urbain, période romaine, ville romaine.

Palavras-chave: Ammaia, civitas, Marvão, paisagem urbana, período romano, villa romana.

A expansão territorial desenvolvida pelos romanos na Península Ibérica teve na base o poder militar das legiões romanas, a inexistência de uma unidade indígena politicamente organizada e as próprias condições orográficas das regiões meridionais. Os romanos teriam atingido a região, hoje Norte Alentejo, por volta de 178 a. C. sob o comando de L. Postúmio Albino, embora a consolidação desse domínio só se efectivasse com Décimo Júnio Bruto, a partir de 138 a. C.

Após a pacificação da região ter-se-ia verificado uma fase de transição, em que alguns povoados indígenas foram romanizados, mantendo-se ocupados pelo menos até aos finais do século I a. C., como atestam alguns materiais recolhidos no Castelo dos Vidais, Corregedor e Água Formosa. A orografia e as reduzidas dimensões destes povoados ${ }^{1}$ comportavam uma demografia pouco significativa, inviabilizavam a sua transformação segundo os modelos de povoamento romanos, sendo mais viável a criação de um novo aglomerado, $\mathrm{Ammaia}^{2}$. É provável que a sua fundação se relacione com a reforma políticoadministrativa de Augusto, desenvolvida a partir de 13 a. C., desempenhando

\footnotetext{
${ }^{1}$ Apesar das excelentes condições estratégico-defensivas que o sítio de Marvão encerra, segundo informação oral, cedida pela arqueóloga Cláudia Pereira, os trabalhos de acompanhamento arqueológico e as sondagens realizadas no âmbito da implantação de infraestruturas no Castelo de Marvão não revelaram vestígios arqueológicos anteriores ao período romano.

${ }^{2}$ A cidade romana de Ammaia localiza-se no vale da Aramenha, no lugar e freguesia de S. Salvador da Aramenha, concelho de Marvão, distrito de Portalegre.
} 
um papel fundamental no contexto da reorganização administrativa e da urbanização da Lusitania.

O aglomerado urbano tinha um significado de centro espiritual, sagrado e jurídico surgindo materializado no núcleo construído, traduzindo-se numa inovação na paisagem da região. O padrão de povoamento romano assentava numa base política, económica e administrativa, materializada não apenas nos aglomerados urbanos, mas também nos vici, nas villae e nos casais, alterando assim os conceitos de ocupação e exploração da paisagem.

A grande ara dedicada ao Génio do Ópido Constituído (J. Encarnação, IRCP: n. ${ }^{\circ}$ 604) poderia relacionar-se com a fundação do aglomerado amaiense. A expressão "oppidum constituti" tem sido interpretada no sentido de estabelecido e organizado politicamente, subentendendo a existência de um núcleo urbano. A mesma expressão pode também enquadrar-se com a atribuição do ius latii, concedido a diversos oppida ${ }^{3}$.

A escolha do sítio para implantação do aglomerado vai de encontro a uma fundação de raiz, preenchendo alguns requisitos enunciados por Vitrúvio (5.10), como a existência de recursos hídricos (rio Sever, ribeira dos Alvarrões e nascentes superficiais do Olheirão e Olhos de Água), a proximidade de um vale agrícola e o resguardo dos ventos. A proximidade de uma zona rica em minerais, como a Serra de S. Mamede, pode ter sido determinante (foto 1).

Tratando-se de uma fundação de raiz e o facto de o sítio apresentar uma topografia regular leva-nos a admitir a ortogonalidade da malha urbana, traçada a partir do cardo maximus (noroeste-sudeste) e do decumanus maximus (nordeste-sudoeste). Estes teriam sido os eixos estruturantes a partir dos quais se traçaram paralelamente as restantes ruas e respectivos quarteirões. O cardo maximus arrancava da Porta Sul, passava ao lado nordeste do forum e prolongar-se-ia até outra porta, a noroeste. O decumanus maximus passaria ou à frente ou a meio do forum, neste caso através de uma porta lateral. Até ao momento foram identificados dois decumani secundários, o primeiro a sudeste da estrutura E.19 (Estacionamento 2) e o segundo entre as estruturas Q.14 e Q.44 (edifício Quinta do Deão). O alinhamento de quase todas estruturas ${ }^{4}$, segundo os eixos principais ou secundários, vai confirmando o traçado ortogonal (anexo I; foto 1).

A observação da fotografia aérea permite reconhecer o traçado da muralha, ligeiramente rectangular e arredondado nos ângulos, tal como se reconhece no canto este. Encontrando-se os limites da muralha nordeste e sudeste definidos com precisão, a área urbana intramuros parece-nos menor em relação às propostas de alguns investigadores ${ }^{5}$, aproximando-se dos 16 ou 17 hectares. A muralha teria como largura regular $1,20 \mathrm{~m}$ e a sua construção em opus incertum denota bom aparelho, utilizando quase exclusivamente o granito,

\footnotetext{
${ }^{3}$ J. Encarnação (IRCP: n. ${ }^{\circ}$ 604); A. Guerra 1996 22-23; V. Mantas 2000 411-412.

${ }^{4}$ Para já, a única estrutura que apresenta um alinhamento diferente dos cardines, decumani e das próprias construções é P.6 (Porta Sul), que surgiu no período visigótico.

${ }^{5}$ Para Vasco Mantas 2000413 a área da cidade não seria “inferior a 20 hectares", enquanto Joaquim Carvalho, segundo informação oral, considera aproximar-se dos 25 hectares.
} 
com excepção do alicerce onde predomina o calhau rolado. O perímetro da muralha aproximar-se-ia dos $1600 \mathrm{~m}$, podendo a sua edificação prolongar-se por vários imperadores. Na área do edifício do Deão e dos Estacionamentos, a sua construção parece remontar a Cláudio I ou aos primeiros Flávios. O carácter honorífico e simbólico da muralha reúne consenso, até porque a vulnerabilidade do sítio e o momento da edificação não justificariam um investimento defensivo.

Nos Estacionamentos, a presença de uma vala de perfil em $\mathrm{V}$, que acompanha a muralha, parece conter em simultâneo a função de fosso e de cloaca. A cronologia da vala e da muralha parecem contemporâneas, no entanto, podemos considerar que a abertura do fosso, mais simbólico e delimitativo que estratégico, tenha surgido na fase de implantação, sendo posteriormente adaptado a cloaca, ao mesmo tempo que surgia a muralha (foto 4).

As estruturas mais antigas identificadas na área da Porta Sul apontam para a existência de uma entrada original, constituída por duas torres semicirculares e um arco ou porta, tal como propunha Vitrúvio. Talvez os silhares erodidos, que se observam na face externa do alicerce da torre este, pertençam a essa primeira estrutura. Na mesma área, os vestígios das construções ${ }^{6}$ particulares da fase de implantação observam-se a sudoeste do cardo maximus. Os muros apresentam bom aparelho, não ultrapassam os $50 \mathrm{~cm}$ de largura e deveriam pertencer a uma habitação, em que a fachada (P.11) estaria virada para o cardo, ligeiramente mais largo nesse momento. Do outro lado da rua, na área conhecida por peristylum existia também uma construção, de cariz doméstico, à qual associamos as estruturas (Pr.10, Pr.12 e Pr.13) e uma conduta de água, apesar de os limites não estarem definidos (anexo II).

O próprio forum pode ter surgido no final do governo de Augusto, pouco depois da constituição do oppidum. É certo que em 44-45 d. C., governando o imperador Cláudio I, Ammaia já possuía magistrados ou duumviri, o que de certa forma testemunha a necessidade e a existência de um centro da vida política, económica, social e religiosa, o forum. A largura do edifício era de 66 $\mathrm{m}$. Considerando que a sua construção seguiu a regra vitruviana,é aceitável que o comprimento ${ }^{7}$ fosse de $99 \mathrm{~m}$. A ladear o templo e a praça do forum existiria uma colunata, assente na estrutura F.9, e talvez uma linha de tabernae, entre as paredes F.1 e F.2. O templo, provavelmente tetrastilo, apresenta cerca de 17,3 $\mathrm{m}$ de comprimento por 9,50 $\mathrm{m}$ de largura, restando apenas o seu enchimento de opus incertum. O espaço da cella é o que se apresenta mais destruído, detendo cerca de 9,50 m de comprimento ${ }^{8}$. Desconhecendo a arquitectura e as respectivas dimensões da basilica e da curia, a sua localização não andaria

${ }^{6} \mathrm{Na}$ Porta Sul as primeiras estruturas parecem ser P.1b, P.2b, P.11, P.12, P.13, P.14, P.15, P.25 e P.32.

${ }^{7}$ V. Mantas 2000414 propõe que o forum tivesse $99 \mathrm{~m}$ de comprimento. Outra hipótese considera que a fachada do edifício passaria pela estrutura F.11, reduzindo o seu comprimento até aos $88 \mathrm{~m}$, aproximadamente.

${ }^{8}$ J. Oliveira 1996 17-18; J. Oliveira 1999 132; V. Mantas 2000414. 
longe do topo sudeste do forum, junto à entrada. Pela posição que ocupa parece-nos que a estrutura F.10 pertenceria a um desses edifícios (anexo IIIa). A construção da actual Estrada Nacional n. ${ }^{\circ}$ 359, por alturas de 1874, dividiu a cidade em duas partes, sendo a obra responsável pelo maior impacto verificado nas ruínas e que afectou as fachadas do forum e das termas. A escavação de uma área restrita no edifício balnear levou à identificação de um pequeno tanque, que poderia funcionar como frigidarium, e uma natatio, parcialmente escavada. Foi ainda identificado um pequeno compartimento, talvez um vestíbulo, e uma área porticada, possivelmente a palestra. As termas teriam sido edificadas no período dos Júlios-Cláudios, conjuntamente com as primeiras edificações públicas da cidade, dada a sua posição central e a importância que detinham na sociedade e higiene romanas (anexo IIIb).

$\mathrm{Na}$ área do actual edifício da Quinta do Deão surgiram também, em meados do século I d. C., algumas construções domésticas. As estruturas caracterizam-se pela utilização regular do xisto e granito, não ultrapassam os $49 \mathrm{~cm}$ de largura e denotam um bom aparelho. A existência de uma soleira de granito a meio da estrutura Q.14 talvez se relacione com uma taberna ou oficina, voltada para o decumanus secundário, a sudeste. Pouco podemos adiantar em relação a esta construção de forma quadrangular e de pequenas dimensões. $\mathrm{O}$ facto de a habitação surgir adossada à muralha relega-a para uma cronologia ligeiramente posterior, entre o imperado de Cláudio e o início da governação dos Flávios. A sudeste do decumanus poderia existir outra construção de características idênticas, passando a fachada por Q.17 ou por Q.44. Esta construção que se prolonga para sudeste torna-se mais difícil de reconstituir, face às sucessivas sobreposições de estruturas (anexo IV).

Ammaia surgia assim como núcleo urbano, centro político-administrativo, à volta do qual se estendia um vasto território e no qual certamente existiam vici, villae, casais e pequenos sítios. Esta teia de unidades de exploração agro-pecuárias e minerais implicava a existência de uma extensa rede viária, assente em quatro ou cinco vias principais que irradiavam da cidade e que se interligavam por caminhos secundários.

A riqueza mineral da região poderia constituir a base da economia de Ammaia e um dos motores da transformação da paisagem urbana e rural. Lembramos que Plínio9, em duas ocasiões, referiu o aparecimento de cristal de rocha nos "ammaeensibus iugis" e destacou o ouro aluvial do Tejo, conhecendo-se uma exploração no território da cidade. A existência de jazidas de ouro, prata, chumbo ${ }^{10}$, manganês, ferro e hematite, referenciadas na carta

\footnotetext{
${ }^{9}$ Plínio-o-Velho, Naturalis Historia, 37.24 e 37.127: refere em duas ocasiões o aparecimento de cristal de rocha nos Ammaeensibus iugis, que deveriam corresponder às elevações mais próximas da cidade. Plínio 4.115 informa que o rio Tejo era famoso pelas suas areias auríferas: “Tagus auriferis harenis celebrantur". Segundo informação de Joaquim Carvalho, junto ao rio Tejo no sítio do Conhal (Nisa), confirmam-se os vestígios de exploração de ouro aluvial, na época romana.

${ }^{10}$ A propósito da extracção de chumbo, ou da simples utilização, Laranjo Coelho (1924 27) refere que na escavação dos alicerces de uma casa, no lugar do Porto da Espada, se encontraram muitas cantarias e "várias barras de chumbo".
} 
geológica e nos registos mineiros do século XIX (M. Pestana 1992 e 1998), confirmam também a riqueza mineral da região. Também as prospecções recentes, levadas a cabo na área do concelho de Marvão, revelaram algumas áreas de extracção mineral ${ }^{11}$. Não esqueçamos que a cidade se localiza nas proximidades de uma faixa de calcários dolomíticos, constituindo a produção de cal $^{12}$ uma actividade essencial para as principais obras na cidade e na própria região.

As diferentes actividades teriam impulsionado o desenvolvimento e a transformação do núcleo urbano. Dos primeiros edifícios ao abandono da cidade, muitas foram as mudanças ocorridas tanto no domínio público, como privado. A paisagem urbana deve ser entendida como um todo em constante mutação e adaptação e as fases ou momentos de construção que indicamos resultam de uma primeira leitura, que se afigura prematura face à reduzida área escavada. Algumas fases de edificação mais abrangentes poderiam resultar de acontecimentos políticos, militares ou económicos, contrastando com casos isolados ou privados. Convém lembrar que as remodelações domésticas seriam mais frequentes, resultando de factores como o casamento, a herança, a venda, a falência ou mesmo o enriquecimento.

Não se conhecendo com exactidão os motivos que originaram a ascensão do oppidum a civitas, é certo que até 44 ou 45 d. C. Ammaia foi promovida, como demonstra o pequeno cipo dedicado ao imperador Cláudio I (L. Vasconcelos 1935). A cidade continuou o seu percurso ascendente e no mesmo século foi distinguida com o estatuto de municipium. O pedestal dedicado ao imperador Lúcio Vero (E. Hubner, CIL II 158) pelos municip(es) Ammai(enses), data de 166 d. C. e apenas comprova que Ammaia detinha a municipalidade nessa data ${ }^{13}$. É consensual que a atribuição municipal tenha surgido com os Flávios, encerrando um papel mais honorífico e político que administrativo e gerando importantes transformações urbanísticas, à semelhança do que aconteceu noutras cidades peninsulares.

O período dos Flávios pode ter sido uma das fases económicas mais prósperas da cidade, reconhecendo-se um volume significativo de materiais importados. A remodelação da Porta Sul parece ter ocorrido entre o final da governação dos Flávios e Trajano, talvez relacionada com a alteração de

${ }^{11}$ J. Oliveira, S. Pereira, J. Parreira (2007) na Nova Carta Arqueológica do Concelho de Marvão indicam alguns sítios com indícios evidentes de actividades extractivas e de fundição: Serra Fria (n. ${ }^{\circ}$ 97: ferro); Currais de Ferro I (n. ${ }^{\circ} 121$ : ferro); Pitaranha (n. ${ }^{\circ}$ 149: cristal de rocha e granito); Monte Roxo II ou Tapada do Ferro (n. ${ }^{\circ}$ 53: ferro); Ferrarias (topónimo vulgar nas imediações de Marvão); Gavião II (n. ${ }^{\circ}$ 137: escória, fundição); villa da Tapada da Eira (n. ${ }^{\circ} 131$ : escória, fundição); casal das Naves (n. ${ }^{\circ} 130$ : cristal de rocha, escória, fundição); Cova da Moura I (n. ${ }^{\circ}$ 123: calcário, forno de cal romano).

${ }^{12}$ É bem provável que o forno localizado ao lado da Cova da Moura (S. Salvador da Aramenha) remonte ao período romano e que a exploração da gruta se relacione com a cal de melhor qualidade.

${ }^{13} \mathrm{O}$ momento da atribuição municipal reparte-se entre o final do principado de Cláudio I e o período dos Flávios, nomeadamente por acção do édito de Vespasiano, datado de 74 d.C. (A. Guerra 1996 28-29). 
estatuto e a monumentalização de alguns espaços públicos (J. Oliveira 1996 20-21). Surgiram duas torres circulares, apoiadas lateralmente pela muralha, que ao mesmo tempo servia de contraforte. Entre as torres conservaram-se os elementos de granito pertencentes à soleira da porta. $\mathrm{O}$ "arco ou porta da Aramenha" deveria situar-se entre as duas torres, sendo reutilizado na vila de Castelo de Vide em 1710. Das torres arrancavam duas imponentes paredes construídas em opus mixtum (P.3 e P.4), ladeando o cardo maximus. As duas estruturas sustentariam uma abóbada que se prolongaria até um segundo arco, implantado no limite dos lajeados, criando assim uma entrada coberta (foto 2).

Após as torres passou a existir uma praça lajeada, dividida em duas partes simétricas pelo cardo. Cada parte media $21,30 \mathrm{~m}$ de comprimento, por 10,75 $\mathrm{m}$ de largura, sendo constituída por lajes quadrangulares ${ }^{14}$. O lajeado este conservou-se praticamente intacto e a inexistência de seis lajes justificarse-ia pela presença de um pequeno podium. O lajeado oposto foi destruído parcialmente e algumas lajes sofreram um abatimento, devido à cedência do subsolo. O limite de ambos os lajeados seria marcado pela colocação de silhares mais pequenos.

Verificámos que a praça oeste foi edificada sobre estruturas habitacionais datadas da fase de implantação. A monumentalização da entrada da cidade implicou a demolição parcial de um edifício e da fachada, recuando até à estrutura P.21. Ainda não foi possível escavar a área total deste edifício que se prolonga para sul; assim, pouco podemos acrescentar em relação às alterações privadas, levadas a cabo no final do século I d. C. ou inícios do século II. O espaço entre o lajeado oeste, a estrutura P.21 e a torre teria ficado vazio ou eventualmente porticado, se considerarmos que as lajes com molduras quadrangulares, posicionadas no canto sul e na quadrícula 2533 , funcionariam como bases de assentamento de colunas (anexo II).

A nordeste da praça, na área conhecida por peristylum, teriam acontecido mudanças significativas. Segundo a proposta de Vasco Mantas (2000 414), é provável que tenha existido aqui um macellum. A construção de um grande edifício, limitado pelas estruturas Pr.1, Pr.4 (adossada à muralha), P.5 e Pr.5, e ladeado por cellae regulares (C.1, C.2 e C.3) aproxima-se de outros mercados já escavados na Hispania (foto 3), nomeadamente o de Baelo Claudia.

$\mathrm{Na}$ área do edifício da Quinta do Deão, podemos remeter para o período dos Flávios - Trajano a construção das estruturas Q.54 e Q.56, pertencentes a uma domus que se prolonga para sudeste, desconhecendo-se os respectivos contornos. Talvez estejam relacionadas com esta construção as estruturas E.19, E.20 e E.21, adossadas à muralha (M.1b). A pequena conduta de xisto (Q.62) pode também reportar-se ao mesmo período. Ainda nesta fase, mas na área extramuros (Estacionamento 1), teria surgido uma construção de que apenas conhecemos três muros. Não foi possível reconhecer a sua função, porém podemos considerar a presença de uma oficina, face ao elevado de número de escórias recolhidas nas quadrículas contíguas. Um pouco a sudeste

${ }^{14}$ J.Oliveira 1999133 refere que as lajes dos lajeados apresentando uma forma quadrangular não possuem medidas exactas, variando entre os 90 e os $110 \mathrm{~cm}$ de lado. 
teria surgido a estrutura E.13, delimitativa de uma área funerária ou necrópole, que se estenderia até ao rio Sever. As próprias sepulturas 1 e 2 parecem datar do período Flávio a meados do século II. Também a construção do mausoléu, em forma de templo, pode datar do século II. O investimento num edifício fúnebre imponente e de dimensões consideráveis faria sentido se pertencesse a uma família de notáveis, quem sabe se relacionado com a primeira sepultura.

No século II d. C., a cidade mantinha a mesma vitalidade e prosperidade que caracterizou a segunda metade do século anterior. As terrae sigillatae hispânicas secundarizaram as produções itálicas e sudgálicas, destacando-se ainda os vidros importados, abundantes em contextos domésticos.

Confirma-se a existência de um teatro no local conhecido por "Picadeiro", não longe do ângulo oeste da cidade. Observa-se no sopé da encosta um recorte intencional e semicircular, que aproveitou a orografia do terreno para implantação da cavea. Quanto à arquitectura do espaço lúdico pouco podemos adiantar, uma vez que no local só foram efectuadas prospecções geofísicas ${ }^{15}$, indiciando a presença de estruturas na orquestra e scaena. A ausência de vestígios materiais da cavea poderia justificar-se pela existência de uma construção de madeira ou pela reutilização dos silhares. A possibilidade de existirem outros edifícios de espectáculos, anfiteatro e circo, é menos provável, apesar de algumas anomalias observáveis na fotografia aérea levantarem suspeitas.

Em Ammaia, para a primeira metade do século III reconhece-se um vazio de informação, motivado pela dificuldade em reconhecer vestígios materiais exclusivos desse período. Na própria numismática amaiense não se reconhecem muitos espécimes representativos deste período.

No último quartel do século III ou inícios do século IV teriam ocorrido transformações na área envolvente ao lajeado e torre oeste (Porta Sul), verificando-se a demolição de uma construção, à qual pertencia a estrutura P.21. O novo edifício e respectivas estruturas sobrepõem-se e reutilizam o espaço desocupado entre a praça oeste e a torre. Neste local surgiram duas tabernae (C.19 e C.11). As estruturas de aparelho menos cuidado são mais largas, sobressaindo o emprego de silhares nos ângulos e no cruzamento de estruturas. A ocupação ou usurpação de espaços anteriormente públicos tornase evidente.

$\mathrm{Na}$ área do pátio do actual edifício do Deão aconteciam algumas alterações, surgindo a estrutura Q.8, embora interligada às primeiras construções. Este muro seria ainda reutilizado na fase seguinte. No canto este do pátio observase o alicerce de um pequeno anexo (Q.15 e Q.16), que ocupava uma parte do decumanus. Na Sala 5 e 6 emerge uma nova construção limitada por Q.27,

${ }^{15}$ As prospecções geofísicas na área do provável teatro tiveram lugar em 2004 e foram desenvolvidas pela Universidade de Gent (Bélgica). Igualmente realizaram-se prospecções na área onde se prevê a existência de um anfiteatro, um pouco a nordeste do primeiro espaço. 
Q.29 e Q.52, igualmente a usurpar a rua. As construções desta fase denotam um bom aparelho e consistência.

Os resultados das primeiras escavações referem que "a cidade foi obrigada a reforçar a sua fortificação, o que poderá ter ocorrido durante o século IV" (Oliveira 1996 20-22). Não refutando para já este cenário, também não o podemos corroborar, dado que não registámos indícios relacionáveis com um eventual reforço defensivo. A avaliar pelo volume de materiais importados, como terrae sigillatae hispânicas e africanas ${ }^{16}$, vidros e objectos de adorno de pasta vítrea, característicos do século IV - meados do século V, a cidade aparenta manter alguma prosperidade.

Sob o actual edifício do Deão verificaram-se importantes alterações, ditadas pela desmontagem das primeiras estruturas. Estas deram lugar a novas construções mais robustas, melhor alicerçadas e encostadas à muralha, mantendo no entanto a reduzida dimensão. Perante a arquitectura das construções, os elementos materiais e a posição que ocupavam na cidade parecem ser de famílias modestas, com algum poder económico, o que lhes permitia adquirir produtos importados (sigillatae, vidros e objectos de adorno de pasta vítrea). Aliás, a identificação de várias lareiras numa área restrita, leva-nos a considerar a existência de várias culinae e de várias famílias numa área restrita.

A realidade seria bem diferente do outro lado do cardo secundário, na área que designámos por sanitários. Os vestígios de duas passagens de ar quente, sob as estruturas Q.37 e Q.38, indiciam a existência de pavimentos aquecidos e de umas termas privadas. É ainda provável que o compartimento Cq9.2 tivesse funcionado como praefurnium.

Os primeiros contingentes godos (Suevos, Alanos, Vândalos Asdingos e Vândalos Silingos) chegaram à Hispania em 406, gerando alguma instabilidade e transformação nas cidades hispânicas. Desmistificada a ideia de "invasões bárbaras" e de destruição massiva, a vinda de novas populações teria causado maiores danos na esfera político-administrativa, social e económica, do que na estrutura urbana. As elites hispano-romanas viam assim os seus cargos políticos e os próprios bens ameaçados, perante alguma instabilidade militar, pilhagens pontuais e o controlo de algumas cidades estratégicas (H. Catarino 2004).

Não se registando indícios de conflito militar em Ammaia, a presença de populações de origem goda assenta em escassos elementos materiais, destacando-se uma fivela de cinturão, um anel de bronze e com algumas dúvidas, dois colunelos de mármore ${ }^{17}$. As remodelações ocorridas entre o final

\footnotetext{
${ }^{16}$ Ao longo do século IV - inícios do século V a cidade recebe ainda grande quantidade de terra sigillata hispânica e de origem africana.

${ }^{17}$ Os materiais considerados visigóticos foram recolhidos nas escavações de 1995 a 1998 , desconhecendo-se o contexto arqueológico exacto. A fivela de cinturão de bronze apresenta-se decorada com círculos, marcados a punção e pintados a ouro (séc. V). Os colunelos de mármore foram recolhidos à entrada da torre este (Porta Sul). Afonso Paço (1953 111-112) refere também que na cidade foi recolhido um triente, cunhado sob Justino I (518-527).
} 
do século V e os inícios do século VI talvez se possam relacionar com a vinda de famílias bárbaras. Na Porta Sul surgem algumas alterações que evidenciam um cenário de abuso e usurpação dos espaços públicos, localizados junto às torres. A construção de estruturas anexas às torres criou uma espécie de átrio que, ao aproveitar o espaço vazio, poderia favorecer a presença de uma maior guarnição.

Na zona do pátio do edifício do Deão surge uma pequena construção adossada à muralha e relacionada com os edifícios anteriores. A identificação da lareira L.3 não deixa dúvidas quanto à função do compartimento Cq.9b, que passou a funcionar como cozinha. A deposição de um conjunto de cinquenta e um bronzes sob o pavimento desta divisão encerrava uma função apotropaica, numa fase em que o valor real das moedas seria reduzido. Ainda nesta fase e nas traseiras do actual museu, as termas baixo-imperiais e os pavimentos aquecidos teriam sido desmontados e adaptados a simples espaço habitacional.

A presença de algumas lucernas paleocristãs constitui uma prova de que o cristianismo já se encontrava enraizado na cidade no século IV. Apesar da inexistência de vestígios, podemos considerar no espaço urbano ou na área envolvente a presença de uma basílica paleocristã.

A partir do século VI começam a escassear os materiais importados, nomeadamente sigillatae e vidros. Nesta centúria a cidade pode ter mergulhado numa conjuntura desfavorável sem precedentes. A insegurança das rotas comerciais, a inflação e a crise financeira que apenas reconhecia a cunhagem do ouro, foram regionalizando a actividade produtiva e o próprio mercado. As elites hispano-romanas vão abandonando a cidade, fixando-se nos seus domínios rurais, cada vez mais feudais e auto-suficientes.

A segunda metade do século VI ficou marcada por um movimento de centralização do poder na monarquia visigoda, recebendo maior oposição por parte das elites eclesiásticas regionais, cada vez mais agarradas ao poder político, aos privilégios e ao património. As lutas pelo poder geraram algumas rebeliões, culminando numa espécie de guerra civil. Por seu turno, a monarquia visigótica implementou um conjunto de medidas centralizadoras que imitavam o poder político-administrativo romano do Baixo-império.

Entre a segunda metade do século VI e o século VIII a estrutura urbana amaiense registou ligeiras alterações no pátio e nas traseiras do actual museu. No pátio surge uma lareira de grandes dimensões (L.4) e a própria cozinha é alargada, através da desmontagem de Q.11 e da mudança da entrada para o canto oeste. A sudoeste, o compartimento Cq.6 passou a funcionar como alpendre. Ao lado, no compartimento Cq.1 reconhecemos outra lareira (L.5), de menores dimensões. Esta divisão funcionava em simultâneo como cozinha e espaço de armazenamento, perante a identificação de dois dolia ${ }^{18}$, in situ (d.1 e d.2), e o negativo de um terceiro (d.3).

Não dispondo para o forum de informações de âmbito cronológico, as escavações no canto oeste revelaram algumas estruturas tardias. Ali foi

${ }^{18}$ Em 2001, as escavações no pátio do edifício da Quinta do Deão revelaram dois dolia, um intacto e o outro fragmentado. O primeiro serviria para guardar azeite e o segundo fora ali 
construído um muro de pedra solta e duas colunas de tijolos, ligados por terra. Na quadrícula A-704 registou-se também uma estrutura que subdividia a cave da ala nordeste. Estas estruturas poderão reportar-se ao final do período visigótico ou islâmico, transparecendo a perda de funções do edifício e a sua reutilização com outro intuito.

O poder crescente das elites religiosas, ao longo do século VII, consolidouse em parte com a adopção do cristianismo como religião oficial visigótica, em 589. Não existindo documentos que refiram Ammaia como sede de bispado, certamente teria sido uma paróquia detentora de um corpo eclesiástico e de uma basílica cristã, talvez situada na zona limítrofe, onde se viria a implantar a aldeia de S. Salvador da Aramenha.

A extinção da cidade enquanto centro político-administrativo pode ter acontecido no século VII ou VIII, motivada por um conjunto de factores e não apenas por um acontecimento isolado ou cataclismo. Parece-nos que uma conjuntura desfavorável e continuada poderia afundar progressivamente a cidade, gerando difíceis condições de vida à população. Entre o final do século VI e meados do século VIII verifica-se uma proliferação de casais e pequenas aldeias a norte da crista quartzítica de Marvão. É provável que este processo de ruralização e o novo padrão de povoamento Alto Medieval tenha culminado no esvaziamento progressivo da cidade. Estaria em causa a própria sobrevivência dos mais desfavorecidos, ou seja o grosso da população.

As constantes lutas pelo poder entre as elites religiosas e a nobreza visigótica, longe de satisfazerem as necessidades civis, acabariam por beneficiar a implantação do invasor muçulmano a partir de 711. É possível que pela cidade tenha passado uma milícia islâmica no primeiro quartel do século VIII. Estudos recentes ${ }^{19}$ apontam no sentido de a cidade se manter ocupada nos primeiros séculos do período islâmico. Algumas cerâmicas recolhidas na área do Estacionamento 2 e na área da Porta Sul sugerem cronologias dos séculos VIII-IX, reforçando a ideia de continuidade. Algumas construções mais tardias podem ter sido edificadas no período islâmico e neste contexto apontamos estruturas na entrada da cidade (P.7, P.10, P.34, P.26 e P.31), no edifício do Deão (Q.13) e no Estacionamento 2 (E.19).

Na gruta da Cova da Moura, situada nas imediações da cidade, foram recolhidos alguns fragmentos de caçoilas e pequenos potes, datáveis do século $\mathrm{X}-\mathrm{XI}$. Estes vestígios comprovam que ainda se exploravam alguns recursos minerais. Aliás, a alusão de Al-Himyari ao cristal de rocha, quarenta milhas a norte de Badajoz pode relacionar-se com Ammaia e com a extracção daquele mineral semiprecioso (A. Guerra 1996 12). Uma questão ainda em aberto prende-se com a decadência, a queda e a transformação da cidade num campo de ruínas. A perda de estatuto e função teria ocorrido entre o século VII e VIII, acarretando consequências profundas no tecido social e alterações na paisagem urbana e mesmo rural. A memória popular justifica o desaparecimento da

reutilizado, depois de reparado com gatos de chumbo.

${ }^{19}$ J. De Meulemeester, J. Dewwulf, M. Grangé (2003), Rapport de Terrain provisoire conçu à Marvão. Universidade de Gent - Fundação Cidade de Ammaia. Julho-Agosto (não publicado). 
cidade com algumas lendas que referem um terramoto, uma inundação e uma catástrofe que a engoliu de terra (J. Oliveira 1998 e 1999).

As primeiras escavações na Porta Sul revelaram que "entre os séculos VI e IX da nossa era a cidade de Ammaia, já em decadência, sofreu os efeitos de um cataclismo que ao soterrá-la a conservou" (J. Oliveira 1999 130). Parece-nos que uma inundação apenas afectaria a área mais baixa da cidade, topograficamente, não constituindo motivo de abandono da urbe. As escavações que orientámos, nas áreas mais baixas da cidade, não forneceram vestígios de catástrofe. Em nossa opinião o abandono teria sido gradual e não precipitado, concordando com Vasco Mantas (2000 417), que concebe a cidade "como tantas outras, decaindo progressivamente até se transformar num campo de ruínas com uma população residual".

O declínio das principais actividades económicas teria convergido numa conjuntura desfavorável, onde a secundarização, a desagregação do poder municipal e a inércia administrativa foram afluindo num processo irreversível. Outro sinal da perda de influência reconhece-se no facto de a cidade não ter sido sede episcopal, numa época em que o poder religioso emerge como força política e social.

O século IX ficou popular pelas inúmeras revoltas levadas a cabo por alguns rebeldes, como Xurumbaqui e Ibn Maruán. Por volta de 875, depois do saque da região entre Coimbra e Santarém, Ibn Maruán teria seguido para o Alto Alentejo e Beira Baixa, até à cidade de Asitanya (H. Catarino 2004 279-282). Num período de instabilidade político-militar, a cidade tornava-se vulnerável, perigosa e sujeita a pilhagens esporádicas. $\mathrm{O}$ aparecimento do hisn de Marvão e talvez do de Vide ${ }^{20}$ teria implicado a desvitalização e abandono de Ammaia, sendo mais fácil construir uma fortificação de raiz em local estratégico, que recuperar ou fortificar a cidade. Aliás, a edificação de uma fortaleza na crista quartzítica de Marvão ou no cume de Castelo de Vide só se justifica num cenário de instabilidade político-militar. Não esqueçamos que a cidade foi edificada num sítio vulnerável, tornando-se num alvo fácil.

A degradação, a falta de manutenção e o consequente desmoronamento de edifícios públicos e privados conferiam à cidade um cenário de degradação e abandono. A cidade, sem estruturas municipais capazes de recuperar, ia agudizando as já difíceis condições de vida das famílias mais persistentes. A emergência de dois novos centros político-militares islâmicos teria contribuído definitivamente para a morte de Ammaia.

O abandono efectivo da cidade teria ocorrido entre o século IX e os inícios do século XI, transformando irremediavelmente a paisagem urbana num campo de ruínas. A eventual presença de uma basílica paleocristã na zona limítrofe da cidade pode ter fixado alguns habitantes, nascendo ali ao lado uma pequena aldeia, hoje S. Salvador da Aramenha. Ao longo da muralha

${ }^{20}$ J. De Meulemeester, J. Dewwulf, M. Grangé, op.cit., p. 3: "En principe, ce découpage supposé pourrait remonter au X siècle, puisque un texte de Ibn Hawqal, mentionnerait Castelo de Vide comme hisn". 
nordeste surgia uma via externa e entulhava-se a cloaca-fosso, facilitando a circulação ao longo do vale da Aramenha.

A cidade pereceu, mas o sítio nunca deixou de ser ocupado e reutilizado. As ruínas funcionaram por mais de um milénio como pedreira, irradiando dali muitas pedras e elementos arquitectónicos para outros destinos. Em Marvão e nas suas aldeias, na vila de Castelo de Vide e mesmo na cidade de Portalegre foram reutilizadas cantarias romanas que deram vida a novas construções. No interior da cidade foram reutilizadas tardiamente algumas estruturas e construções, observando-se também algumas sobreposições. Recorde-se que o forum serviu de curral de ovicaprinos, a torre oeste foi reconstruída e o macellum modificado.

A reconstrução da torre Oeste teria ocorrido no período Moderno, surgindo talvez como contraforte do arco, ou como construção anexada. O aparelho original era de opus mixtum, mas a sua reconstrução foi efectuada em opus incertum, de má qualidade. A reedificação foi executada a partir da trave da porta, coincidente com o topo da unidade estratigráfica superficial ou nível de circulação agrícola. A reconstrução da torre só se observa na metade interna e o traçado romano não foi respeitado pela nova edificação, verificando-se um desvio para o interior da cidade. Parece-nos que a reconstrução tinha outra função e no momento da reedificação a parte romana estaria parcialmente soterrada, o que justificaria o desvio.

Também na área do provável macellum teria surgido uma construção quadrangular, encimada por colunas, estas construídas à base de materiais romanos reutilizados. Reconhecemos a semelhança entre as estruturas e um peristylum, porém preferimos interpretar esta construção como sendo o suporte de uma latada, cujas semelhanças reconhecemos em estruturas de propriedades agrícolas da região. Convém não esquecer que as próprias estruturas Pr.3, Pr.8 e Pr.21 foram edificadas na actualidade, para apoio da actividade agrícola.

No século XVI, os humanistas Amador Arrais e André de Resende ainda observaram "em todo o valle \& várzea de Aremenha muytas torres \& pontes sobre o Rio Sever, lastros \& solhos de casas nobres bem ladrilhados, \& lageados, \& hum cano de agoa doce, que de hũa fonte corria pela cidade, muros derribados..." (A. Arrais 1589 241-242).

Lentamente, a paisagem urbana foi-se desmontando. As ruínas transformaram-se em pedreira e mais tarde em campo agrícola. As pedras e as cantarias da antiga cidade romana favoreceram a construção de novas casas ou aldeias, contribuindo para a transformação da paisagem, hoje, marcadamente rural. 


\section{Anexos}

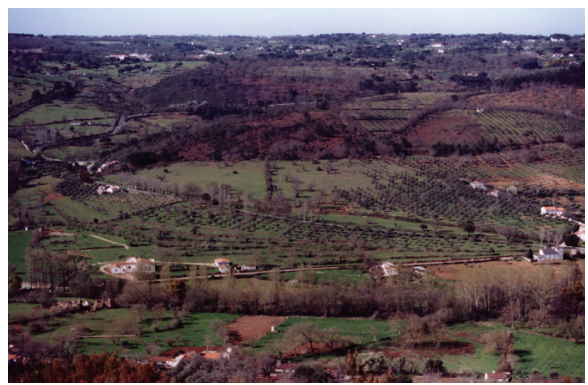

Foto 1: Vista geral de Ammaia, implantada no Vale da Aramenha

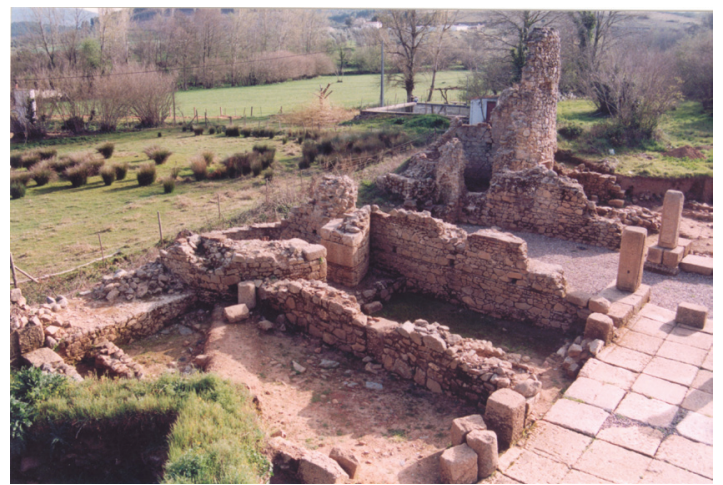

Foto 2: Porta Sul (torre e praça este, cardo maximus e torre oeste)

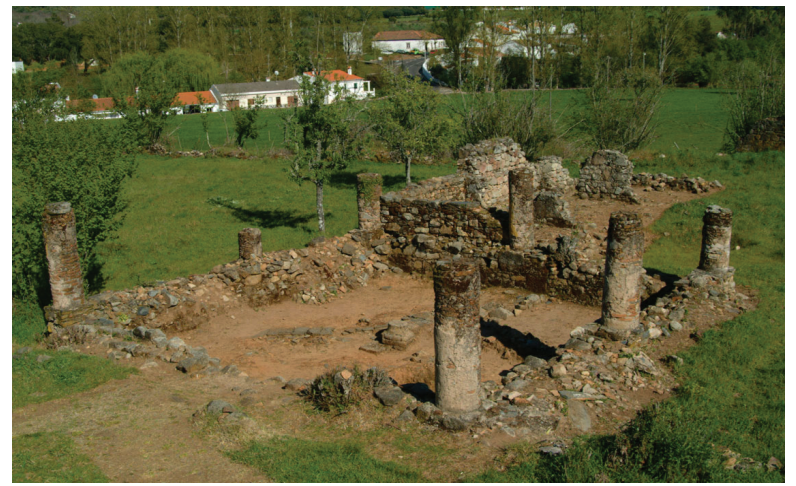

Foto 3: Peristilo ou latada, implantado sobre o provável macellum 


\section{Sérgio Pereira}

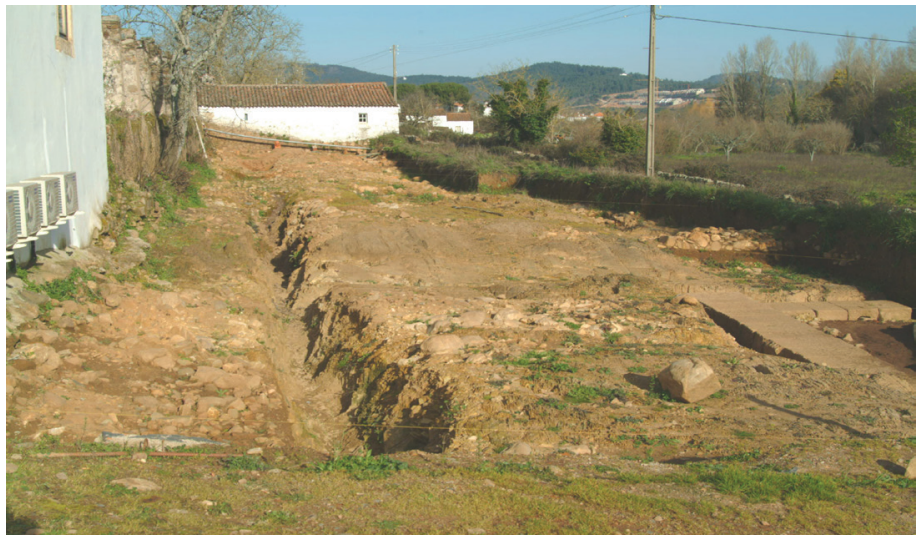

Foto 4: Estacionamento 1 - cloaca-fosso paralela ao museu e à muralha; à direita observa-se parte de um mausoléu

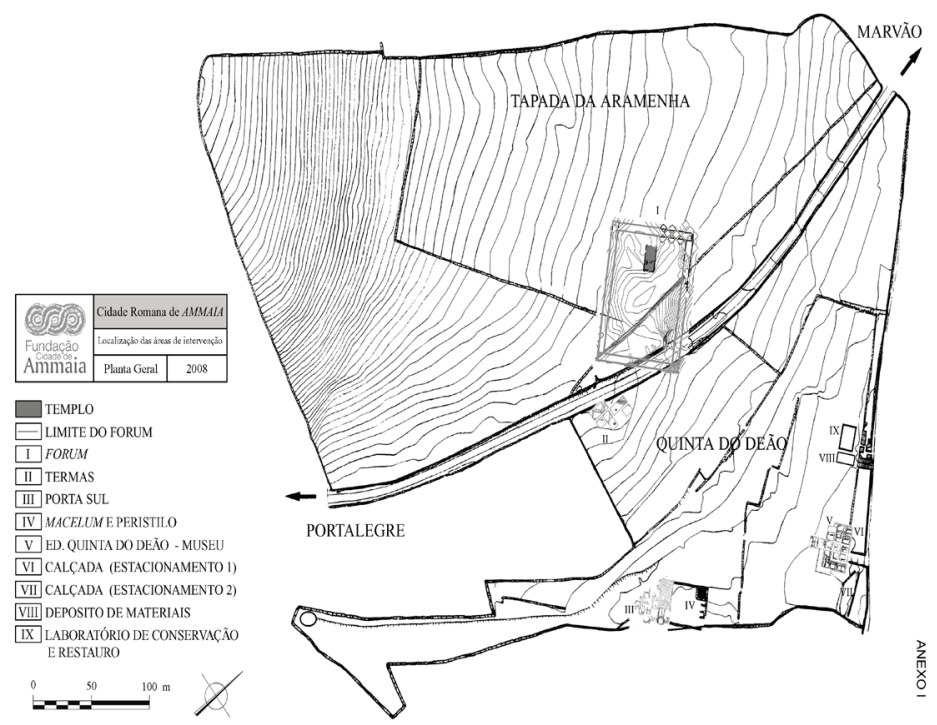

Fig.1. Área da cidade de Ammaia 


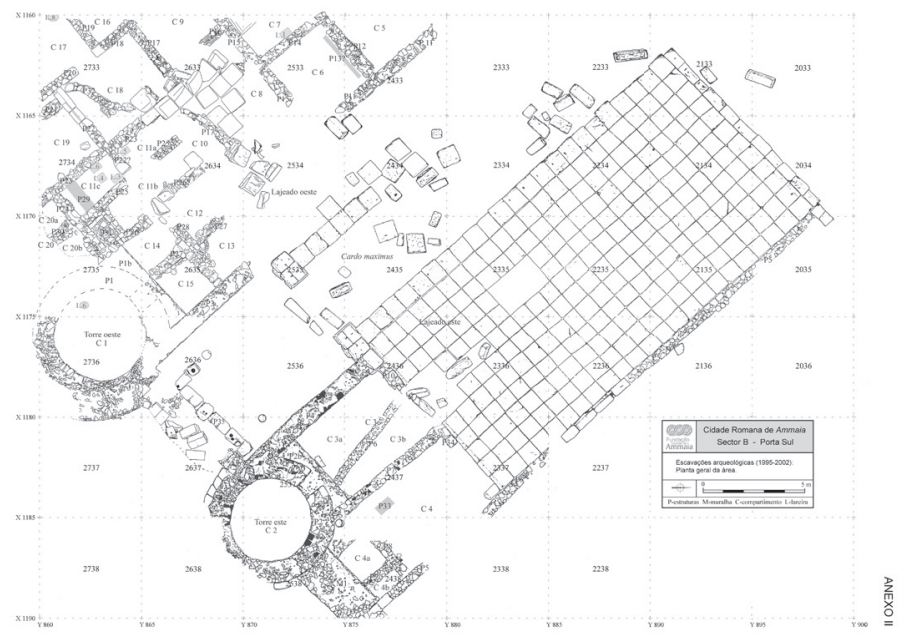

Fig.2. Porta Sul

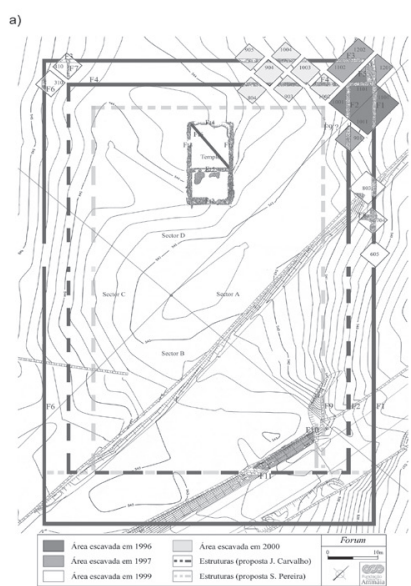

ANEXO III

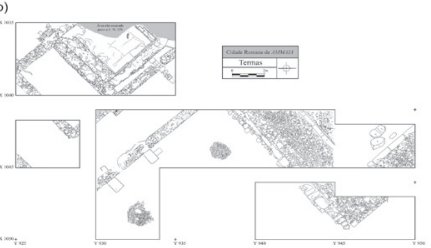

Fig.3. Forum (Mantas 2000) e termas (Relatório de Progresso 2002) 


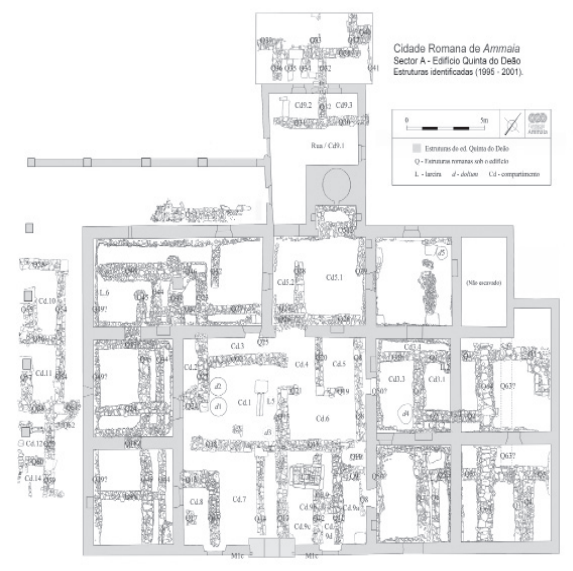

Fig.4. Edifício Quinta do Deão - actual museu

\section{Bibliografia}

Helena Catarino (2004), "A ocupação Islâmica”, in João Medina, dir., História de Portugal. Madrid, Ediclube, $3^{\circ}$ Vol., 279-282.

José d' Encarnação (1987), "A população romana do nordeste alentejano", in Actas das I Jornadas de Arqueologia do Nordeste Alentejano (1985), Castelo de Vide, 167-170.

Amílcar Guerra (1995), Plínio-o-Velho e a Lusitânia. Lisboa, Colibri.

Amílcar Guerra (1996), "Ammaia, Medobriga e as ruínas de S. Salvador de Aramenha: dos antiquários à historiografia actual”, A Cidade, Revista Cultural de Portalegre 11 7-33.

E. Hubner (1869), Corpus Inscriptionum Latinarum (CIL). Berlim. Vol. II.

IRCP: José d' Encarnação (1984), Inscrições Romanas do Conventus Pacensis. Coimbra, Instituto de Arqueologia da Faculdade de Letras.

Vasco Gil Mantas (2000), "A sociedade luso-romana do município de Ammaia", in Sociedade y Cultura en Lusitania Romana. IV Mesa Redonda Internacional, Mérida, Série Estudios Portugueses, 13 391-420.

Jorge de Oliveira, Isabel C. Fernandes, J. Caeiro (1996), "Cidade romana de Ammaia", Ibn Maruan 6. Câmara Municipal de Marvão, Lisboa, Colibri, 15-22.

Jorge de Oliveira, Isabel C. Fernandes, José O. Caeiro (1999), "Cidade romana de Ammaia, S. Salvador de Aramenha, Marvão, Portugal", in Actas do II Congresso de Arqueologia Peninsular. Zamora, Fundação Rey Afonso, Universidade de Alcalá, 129-134.

Jorge de Oliveira, Sérgio Pereira, João Parreira (2007), "Nova Carta Arqueológica do Concelho de Marvão", Ibn Maruán 14. Câmara Municipal de Marvão, 
Lisboa, Colibri.

Afonso do Paço (1953), "Carta arqueológica do concelho de Marvão”, in Actas do XIII Congresso Luso-Espanhol para o Progresso das Ciências (1950), $7^{\text {a }}$ secção, Ciências Históricas e Filológicas. Lisboa, Associação para o Progresso das Ciências, 93-127.

Manuel Inácio Pestana (1992), "Novos registos mineiros na região de Portalegre no período fontista", Ibn Maruán 2. Câmara Municipal de Marvão, Lisboa, Colibri, 207-220.

Manuel Inácio Pestana (1998), "Novos registos mineiros na região de Portalegre”, Ibn Maruán 8. Câmara Municipal de Marvão, Lisboa, Colibri, 297-308. 